\title{
ASPECTOS DA PRODUÇÃO ESPACIAL NA REGIÃO DA UNIDADE DE PLANEJAMENTO E GERENCIAMENTO DO IVINHEMA - MATO GROSSO DO SUL - BRASIL
}

\author{
Giovane Silveira da SILVEIRA ${ }^{1}$ \\ André Geraldo BEREZUK²
}

\section{Resumo}

O objetivo do presente trabalho consiste em verificar alterações na estrutura produtiva da Unidade de Planejamento e Gerenciamento (UPG) Ivinhema. Neste sentido faz-se o exame do quanto a estrutura produtiva de cada município difere da estrutura produtiva da UPG Ivinhema, e o quanto a estrutura produtiva dos municípios que a compõe apresentaram modificações entre o período de 1995 - 2014. A metodologia da presente pesquisa contempla técnicas estatísticas que intentam mesurar o desenvolvimento regional, como o Coeficiente de Especialização e o Coeficiente de Reestruturação, além das curvas de Lorenz e o índice de Hoover. Como resultado obtido, percebe-se uma estratégia de ação do mercado internacional e dos atores regionais, pois constatou-se que mesmo com as alterações na estrutura produtiva em alguns municípios, no período estudado, ainda assim isto não significou, necessariamente, mudança no padrão de produção, o qual continua assentado sobre o tripé "grãos x insumos agrícolas (ração animal) x setor pecuário". Portanto, considera-se que a estrutura produtiva territorial da UPG Ivinhema é conduzida por um mercado de forte apelo ao acúmulo/ valorização do capital oligopolista sob o impulso do esquema soja-ração-carne.

Palavras-chave: Estrutura Produtiva. Desenvolvimento Regional. Unidade de Planejamento e Gerenciamento do Ivinhema.

\footnotetext{
${ }^{1}$ Doutorando em Geografia pela Faculdade de Ciências Humanas - UFDG. Docente na Universidade Estadual de Mato Grosso do Sul - UEMS. Pesquisador do GEFTA - Grupo de Estudos sobre Fronteira, Território e Ambiente - UNIOESTE. Rua: Itibiré Vieira, s/n; Bairro: Residencial Júlia de Oliveira Cardinal; CEP: 79907-414;Cidade: Ponta Porã; Estado: Mato Grosso do Sul; País: Brasil. E-mail: giovane@uems.br

2 Doutor em Geografia pela Universidade Estadual Paulista Júlio de Mesquita Filho - UNESP. Docente na Universidade Federal da Grande Dourados - UFGD. Rodovia Dourados - Itahum, km 12; Cidade Universitária; Caixa Postal: 364; CEP: 79804 - 970; Cidade: Dourados; Estado: Mato Grosso do Sul; País: Brasil. E-mail: AndreBerezuk@ufgd.edu.br
} 


\section{Abstract}

\section{Land production aspects of the Ivinhema Planning and Management Unity region - Mato Grosso do Sul State - Brazil}

The main goal of this research is to verify if it is occuring changes within the land structural productive sphere at the Ivinhema Planning and Management Unity in Mato Grosso do Sul State, Brazil. For this, we aim to examine how this structural productive sphere is changing between the municipalities and the Ivinhema Planning and Management Unity. Moreover, we will observe how this municipal productive land pattern presented modifications at the period from 1995 to 2014. The methodology is based by statistical techniques that want to measure the regional development, using the Lorenz curve and the Hoover Index. This work shows a clear global market strategy with its regional actors (strategy that emphasizes a non-change land structural producitve sphere, even with presenting modifications inside some regional municipalities production). In other words, the land production continues based on the scheme grains production $x$ land products (industrial food for livestock) $x$ cattle sector. It means that the territorial productive structure of Ivinhema Planning and Management Unity is charged by a market system with a strong call to the oligopolist capital submissed by the land production model (soybeans - animal food - meat).

Key words: Productive Structure. Regional Development. Ivinhema Planning and Management Unity.

\section{INTRODUÇÃO}

No ano de 2014, Mato Grosso do Sul apresentava um total de 79 municípios, dos quais 25 municípios encontravam-se na Unidade de Planejamento e Gerenciamento do Ivinhema (Figura 1), onde a rede hidrográfica de tal região tem, como rios principais, o Vacaria, o Brilhante, o Dourados e o Ivinhema.

Como elementos fisiográficos da região de estudo, pode-se mencionar, a oeste, a Serra de Maracajú, com uma altitude de até 736 metros, onde nascem os rios Vacaria, Brilhante e Dourados e, a leste, a calha do rio Paraná com uma altitude de 195 metros, onde está a foz do rio Ivinhema. Por conseguinte, o escoamento do fluxo hidrológico de tal região se dá no sentido noroeste para sudeste. Ainda no que se refere à Serra de Maracajú, Oliveira, Urchei e Fietz (2000, p. 14) destacam que "a disposição geográfica do relevo e da rede de drenagem configuram, nessa Serra, um divisor de águas entre as drenagens que vertem para a calha do Paraná e as que vertem para a bacia do Paraguai".

Entre os elementos fisiográficos que homogenizam tal região, pode-se elencar a vegetação, o solo, o relevo e o potencial agrícola. No que diz respeito à vegetação, pode-se caracterizar a região como do tipo de área predominantemente antropizada com algumas pequenas porções isoladas de floresta tropical e savana. De acordo com Oliveira, Uriel e Fietz (2000, p. 22) "as áreas florestais foram, em grande parte, substituídas por culturas cíclicas e as áreas de tensão ecológica, savanas e de formação pioneiras, foram transformadas em pastagens". Neste sentido, tomam-se as palavras de Moreira (2015, p. 47) que, ao retratar o espaço geográfico do Brasil, realiza a seguinte afirmação: "O espaço da paisagem é o da monocultura". 


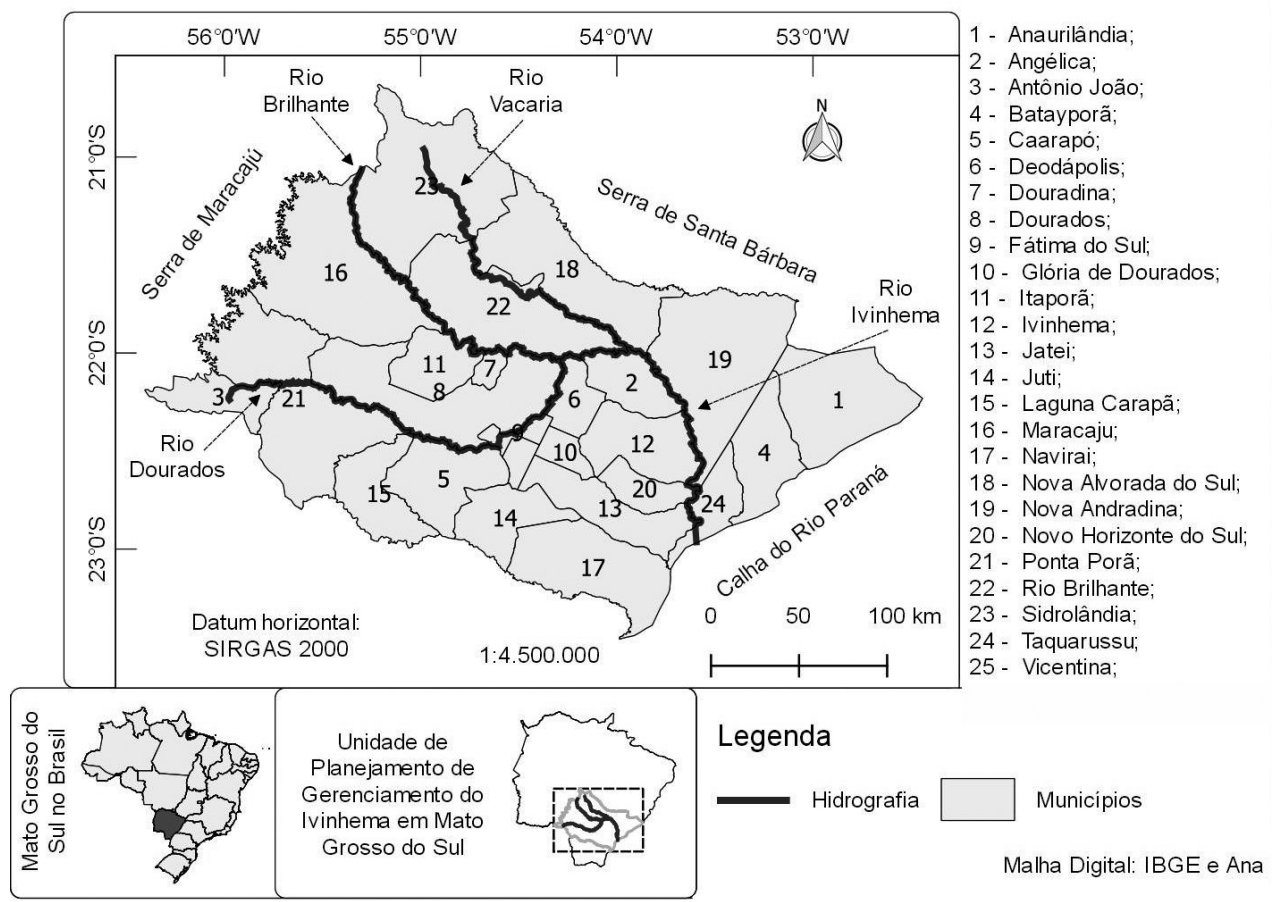

Figura 1 - Unidade de Planejamento e Gerenciamento do Ivinhema

Fonte: elaboração própria a partir de malha digital disponibilizada pelo IBGE Instituto Brasileiro de Geografia e Estatística em MALHA (2018).

A monocultura, também paisagística, do campo compartilha seus efeitos com a natureza das cidades do entorno, que se transfiguram em polos agroindustriais, pois nas décadas de 1980-1990, segundo Moreira (2015, p. 126), pode-se mencionar, a título de ilustração, o modo como a monocultura da "soja se casa à criação de aves e, através desta, à cultura do milho, num consórcio soja-ração-carne", que imprime na região uma reorganização em sua espacialidade também urbana. Desta maneira, ainda de acordo com Moreira (2015, p. 138), em tal região "a cidade é a sede da agroindústria, leva suas relações para o âmbito do trabalho agrário, ao tempo que se cerca de um oceano de soja, pastagens de gado, plantio de milho e uma multiplicidade de granjas".

As características do solo são a baixa fertilidade, de topografia plana e suave ondulada com baixa disponibilidade de nutrientes e excesso de alumínio, o que leva Oliveira, Urchei e Fietz (2000, p. 17) a afirmar que o solo "requer aplicação de corretivos e fertilizantes para viabilizar sua exploração", além do fato de que "a ausência de impedimentos à mecanização conferem-Ihes excelente potencial para a utilização intensiva". Todavia, registra-se a predominância de atividade agropastoril mesmo quando "a mecanização encontra certas restrições nas áreas situadas em relevo mais movimentado" (OLIVEIRA, URCHEI, FIETZ, 2000, p. 20). E, ainda de acordo com os autores citados, trata-se de "uma terra pouco fértil, mas com boas propriedades físicas em topografia suave, será boa ou regular para os sistemas de cultivo com largo emprego de capital e tecnologia". 
Moreira (2015, p. 41) explica como tais lugares servem de atração para atividades de monocultura, pois estes são "pedológica e locacionalmente mutante", o que significa ser tendente a deslocar-se, com frequência, para áreas de solos de menor rentabilidade e nem sempre bem localizadas", sendo esta uma das características do "espaço monopolista" na agropecuária. Assim, torna-se possível entender o fato de porque os "núcleos coloniais que se deslocam para a bacia do Paraná, nos anos 19501960, para a região de Dourados, no Mato Grosso do Sul, nos anos 1960", sendo um resultado espacial que provém da ação das relações sociais de "disputa de espaço que se estabelece entre a cultura de trigo e soja no Rio Grande do Sul nos anos 19401950" (MOREIRA, 2015, p. 126).

Em virtude das características geológicas da UPG Ivinhema, Frata e Faria (2010), dividem a bacia hidrográfica do Ivinhema em duas sub-bacias: a parte Alta correspondente à área entre a Serra de Maracajú e a foz dos rios Vacaria, Brilhante e Dourados, na afluência com o rio Ivinhema; e a parte Baixa, correspondente à área entre o início do rio Ivinhema até a sua foz na calha do Paraná. Oliveira, Urchei e Fietz (2000, p. 16) trazem a informação de que o solo de tal região é formado por $46,2 \%$ de Latossolo Roxo e por 38,5\% de Latossolo Vermelho-Escuro. O Latossolo Roxo "é a classe de maior expressão, concentrando-se na região da Grande Dourados até a borda da Serra de Maracajú, no limite da bacia hidrográfica do rio Paraguai". Já o Latossolo Vermelho-Escuro possui "maior ocorrência na porção leste da bacia", a qual Moreira (2015, p. 33) a caracteriza como "de horizontes menos desenvolvidos e diferenciados e menor grau de fertilidade".

Desta forma, a geologia do alto setor da bacia apresenta, majoritariamente, rochas vulcânicas de composição básica (Formação Serra Geral), e o setor baixo da bacia é formada por sedimentos argilosos, arenosos e cascalhos (Formação Caiuá), sendo ambas formações pertencentes à era Mesozóica. Já com relação ao aspecto referente ao Bioma, o alto setor da bacia pertenceria ao Cerrado, enquanto o baixo setor da bacia apresenta o bioma referente à Mata Atlântica (ver Figura 2).

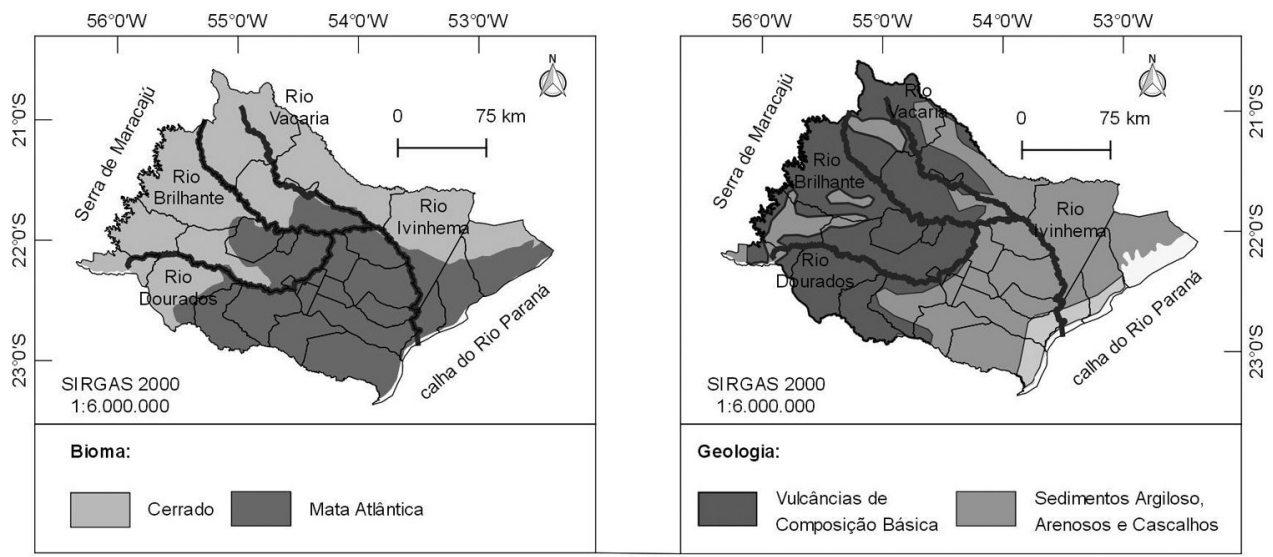

Malha Digital: IBGE - Instituto Brasileiro de Geografia e Estatistica e ANA - Agência Nacinal das Águas

Figura 2 - Aspectos referentes ao Bioma e à Geologia da UPG Ivinhema

Fonte: elaboração própria a partir de malha digital disponibilizada pelo IBGE Instituto Brasileiro de Geografia e Estatística em MALHA (2018). 
Os fatores mencionados no parágrafo anterior levam Frata e Faria (2010, p. 10) a afirmarem "que as terras de melhor aptidão para lavoura estão na parte alta da sub-bacia e as de aptidão mais restrita para a atividade na baixa, onde é regular para pastagens plantadas e silvicultura". Por conseguinte tem-se que "a parte alta está entre as mais importantes regiões produtoras de grãos e a parte baixa tem na produção de gado de corte, inclusive para exportação, sua característica econômica principal" (FRATA \& FARIA, 2010, p. 11). E, ao abordar a Economia Política do Espaço no Brasil, Moreira (2015, p. 40) destaca que é conhecimento comum o fato de "o gado entrando em áreas de mata devastada e a lavoura, nas de campo corrigidos de suas insuficiências de fertilidade".

Por conseguinte, o objetivo do presente trabalho consiste em verificar alterações na estrutura produtiva da UPG Ivinhema. Neste sentido faz-se o exame do quanto a estrutura produtiva de cada município difere da estrutura produtiva da UPG Ivinhema. E o quanto a estrutura produtiva dos municípios que compõe a UPG Ivinhema apresentaram modificações entre o período de 1995 - 2014.

\section{METODOLOGIA}

A presente pesquisa contempla técnicas estatísticas que intentam mensurar o desenvolvimento regional, como o Coeficiente de Especialização e o Coeficiente de Reestruturação, além das curvas de Lorenz e o índice de Hoover. A variável utilizada em tais técnicas foi o valor do emprego formal vigentes em 31 de dezembro nos anos de 1995, 2004 e 2014, cujos dados tem como fonte o Ministério do Trabalho e Emprego (MTE) obtidos por meio da Relação Anual de Informações Sociais (RAIS) e do Cadastro Geral de Emprego (CAGED). Sobre este tipo de informação, Lima e Simões (2010, p. 40) apontam que tais dados possibilitam compreender o processo de crescimento econômico. Todavia, como ressaltam Melo e Simões (2009, p. 57), para tais dados "não há desagregação por posição na ocupação, sexo, idade, salário, tamanho das empresas, entre outros fatores" o que traz limitações para tal base, mas não para o presente trabalho, cuja metodologia expõe-se, de forma sucinta, na tabela 1.

No que diz respeito às Curvas de Lorenz, Lima \& Simões (2010, p. 49) afirmam que "permitem visualizar e interpretar o grau de concentração espacial das atividades econômicas." Tais curvas são desenhadas entre dois eixos: o horizontal representa o percentual total acumulado de participação de emprego formal em atividade econômica $(\rho)$. Já o eixo vertical representa o percentual total acumulado de participação dos municípios $(\phi)$. Uma linha de $45^{\circ}$ graus com origem na intersecção dos eixos representa uma distribuição ideal do emprego para com os municípios, sendo que curvas à esquerda desta linha indicam concentração espacial da atividade econômica. Quanto mais próximo da linha (A-B) estiver a curva, menor a concentração espacial da atividade econômica, quando comparada com uma curva que se aproxime de forma côncava ao canto interior direito formado pelas linhas ( $A-B-C)$, o que indica uma alta concentração espacial, ver figura 3. Para Monasterio (2011, p. 320) "quanto mais concentrado um setor, mais côncava é esta curva e maior a área $(\alpha)$ entre ela e a reta de 45 graus". 


\section{Tabela 1 - Medidas de Desenvolvimento Regional}

\begin{tabular}{c|c|c}
\hline \multicolumn{2}{|c}{ MEDIDAS REGIONAIS } \\
\hline $\begin{array}{c}\text { Coeficiente de } \\
\text { especialização da } \\
\text { região } \mathbf{j}\left(\mathbf{C E}_{\mathbf{j}}\right)\end{array}$ & Equação: & $\begin{array}{l}\text { Definição: } \\
\text { Averigua o quanto da estrutura produtiva da } \\
\text { região apresenta semelhança com a estrutura } \\
\text { produtiva da região de referência. }\end{array}$ \\
\hline
\end{tabular}

Valores próximos de 1 indicam que a estrutura produtiva da região $\mathrm{j}$ diverge da

Condição: estrutura produtiva da região de referência.

$0 \leq C E_{j} \leq 1 \quad$ Para valores próximos de 0 pode-se afirmar que a estrutura produtiva da região é semelhante da região de referência.

\begin{tabular}{c|l|l}
\hline $\begin{array}{c}\text { Coeficiente de } \\
\begin{array}{l}\text { Reestruturação da } \\
\text { região j entre dois } \\
\text { períodos }\left(\mathbf{C T}_{j}\right)\end{array}\end{array}$ & $\begin{array}{c}\text { Equação: } \\
C T_{J}=\frac{\sum_{i}\left(\left|i_{t 1}^{e j}-i_{t 0}^{e j}\right|\right)}{2}\end{array}$ & $\begin{array}{l}\text { Definição: } \\
\text { Verifica se houve mudança na estrutura produtiva } \\
\text { da região } j \text { entre o período inicial }\left(\mathrm{t}_{0}\right) \text { e final }\left(\mathrm{t}_{1}\right) .\end{array}$ \\
\hline $\begin{array}{c}\text { Condição: } \\
0 \leq \mathrm{CT}_{j} \leq 1\end{array}$ & $\begin{array}{l}\text { Se o coeficiente apresentar valores próximos de } 0 \text {, então não houve mudanças na } \\
\text { estrutura produtiva (ausência de especialização); } \\
\text { Mas se os valores forem próximos de 1, então houve mudança na estrutura } \\
\text { produtiva (presença diversificação). }\end{array}$ \\
\hline
\end{tabular}
Em que:

Variável: Definição:

$E_{i 1}$

Refere-se ao emprego do setor i na região j.

$E_{o j}=\sum E_{i j}$

Total de empregos de todos setores para a região $j$.

$E_{i o}=\sum^{i} E_{i j}$

Total de empregos de todas as regiões para o setor i.

$E_{o o}=\sum_{j} \sum_{i} E_{i j}$

Total de empregos de todos os setores i e regiões $\mathrm{j}$.

$\begin{array}{lcc}\text { Variável: } & \text { Condição: } & \text { Sendo que: } \\ i_{j}^{e}=\frac{E_{i j}}{\sum_{i} E_{i j}} & \sum_{i} i_{j}^{e}=1 & i_{0}^{e}=\sum_{j} i_{j}^{e} \\ j_{i}^{e}=\frac{E_{i j}}{\sum_{j} E_{i j}} & \sum_{j} j_{i}^{e}=1 & j_{0}^{e}=\sum_{i} j_{i}^{e}\end{array}$

Fonte: elaboração do autor a partir de Lima e Simões (2010). 


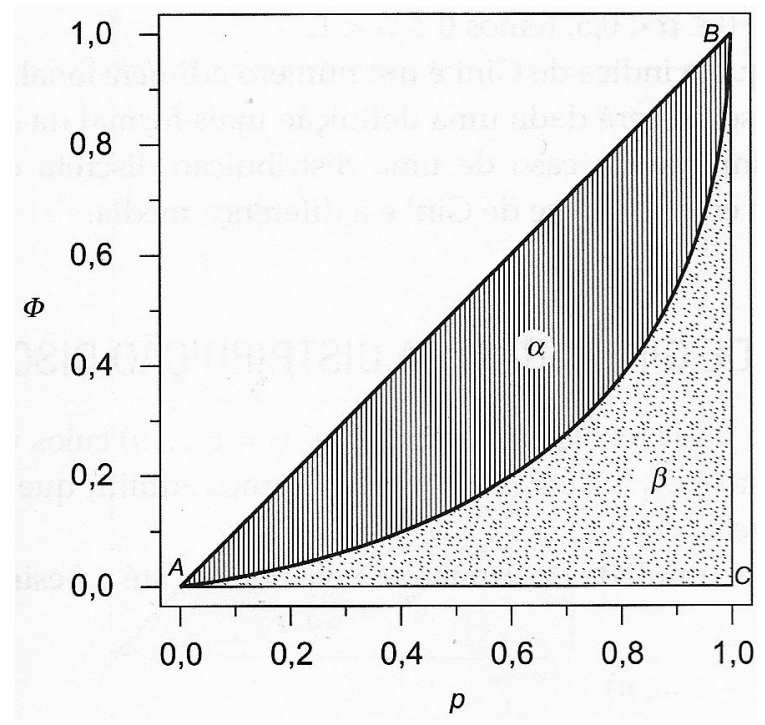

Figura 3 - Ilustração da Curva de Lorenz

Fonte: extraído de Hoffman (2006, p. 337)

Lima e Simões (2010, p. 50) ainda frisam que "a análise da curva de Lorenz pode ser complementada pelo Índice de Gini, já que esse é capaz de mensurar o grau de concentração espacial das atividades econômicas." Segundo Monasterio (2011, p. $320,321)$ "tal como o índice de Gini, o valor do índice de Hoover é dado por $\alpha /(\alpha+\beta)$ ", assim "em um setor $k$ bem distribuído pelas regiões, o índice de Hoover terá valor 0 , e a concentração total implicará um valor igual a 1".

De acordo com Lima e Simões (2010, p. 52) as medidas regionais "permitem identificar o grau de especialização das economias regionais em um período ou o processo de diversificação ocorrido entre dois ou mais períodos".

\section{ANÁLISE DOS RESULTADOS}

Como análise dos dados alcançados, pode-se perceber, por meio da figura 4, que em 1995 o cultivo de cana-de-açúcar revelou uma curva quase alinhada do eixo horizontal até o valor de 0,96 , neste eixo, e menor que 0,10 no eixo vertical. Isto reflete o fato de que em 1995, têm-se 99,53\% dos empregos do cultivo de cana-deaçúcar alocados somente em um município, Naviraí, o que denota uma concentração evidente de tal atividade econômica.

Já, para o ano de 2004, a curva que representa o cultivo da cana-de-açúcar revela um recuo para o valor de 0,8 no eixo horizontal, com ponto equivalente a menos que 0,10 no eixo vertical. Isto ocorre porque, neste ano, o percentual de $59,14 \%$ do emprego em cana-de-açúcar passou a estar concentrado em 2 municípios, Naviraí e Caarapó. 
Ano de 1995

Ano de 2004

Ano de 2014
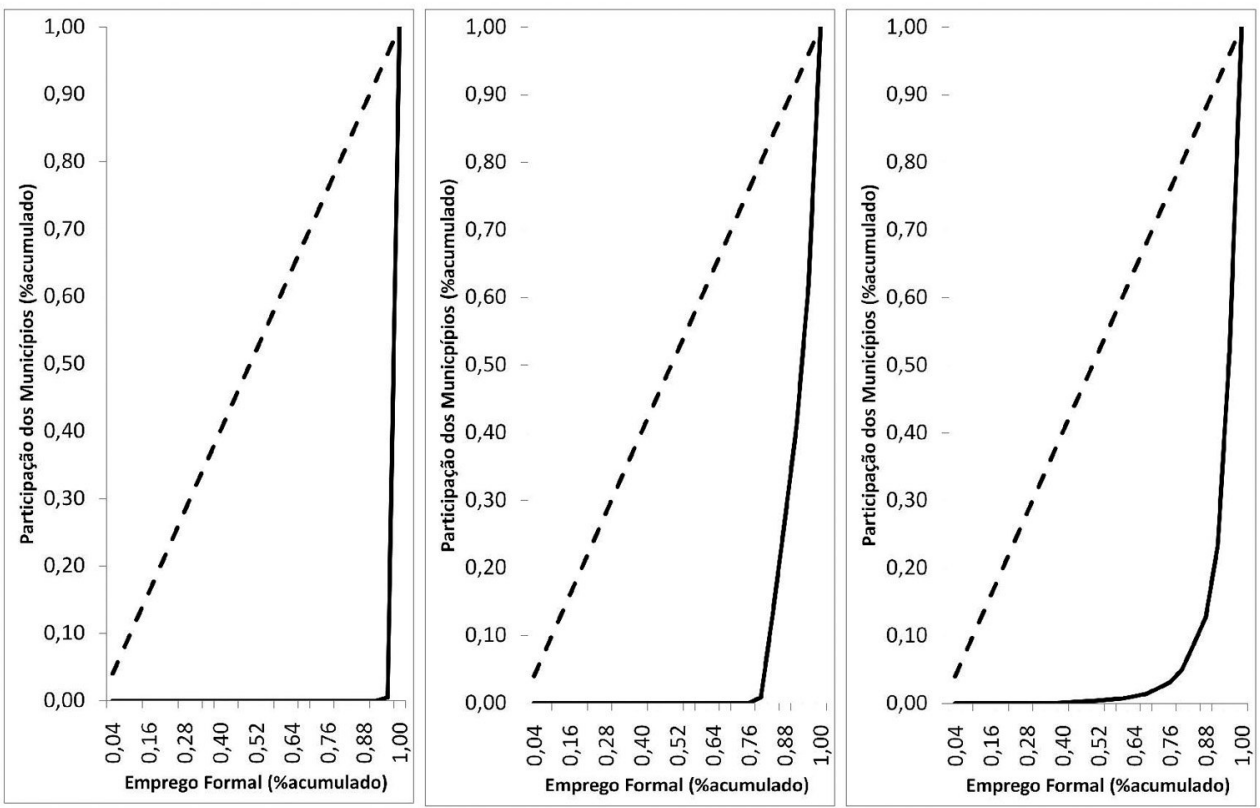

Legenda:

-ー-- Diagonal de $45^{\circ}$

Emprego Formal no setor de Cana de Açúcar

\section{Figura 4 - Curvas de Localização para a Bacia do Ivinhema}

Fonte: elaboração própria a partir dos dados de RAIS-CAGED-TEM, disponível em BRASIL (2018).

E, no ano de 2014, ocorreu um aumento no número de municípios que apresentaram cultivo de cana, como pode-se perceber pela figura 4 . Todavia, a quantidade de emprego, em tal atividade, continua concentrada em alguns municípios, como pode-se averiguar por meio do índice de Hoover na tabela 2.

Na figura 5, destaca-se a expansão da atividade de cultivo de cana-de-açúcar na região da bacia. Todavia, sua concentração realiza-se nos municípios de Caarapó e Naviraí, em razão da complementaridade de fatores, dada pelas condições geográficas, como a elevada permeabilidade hídrica e ausência de impedimentos à mecanização (Oliveira, Urchei e Fietz, 2000, p. 17). Soma-se a isso algumas características locacionais, como área de expansão para arrendamento a custos mais baixos que o principal Estado produtor (São Paulo, vizinho de Mato Grosso do Sul) e o aumento da demanda interna, que gerou linhas de crédito e investimentos por grupos privados, como alguns tradicionais produtores do Nordeste (como Tavares de Melo) e outros entrantes, atraídos pelas margens de lucro (como a Odebrecht Industrial). 
Tabela 2 - Índice de Hoover para a Unidade de Planejamento e Gerenciamento do Ivinhema

\begin{tabular}{ccccccccc}
\hline & Cereais & Cana & Soja & Bovinos & Suínos & Aves & S.Agro & S.Pec \\
\hline 1995 & 0,78 & 0,96 & 0,81 & 0,45 & 0,88 & 0,87 & 0,81 & 0,65 \\
\hline 2004 & 0,79 & 0,84 & 0,70 & 0,45 & 0,81 & 0,86 & 0,76 & 0,70 \\
\hline 2014 & 0,70 & 0,87 & 0,69 & 0,43 & 0,76 & 0,86 & 0,65 & 0,62 \\
\hline
\end{tabular}

Fonte: elaborado pelos autores a partir dos dados de RAIS-CAGED-MTE. Onde "S.Agro" à Serviços para Agricultura e "S.Pec" corresponde à Serviços para Pecuária. Fonte: elaboração própria a partir dos dados de RAIS-CAGED-MTE, disponível em BRASIL (2018).

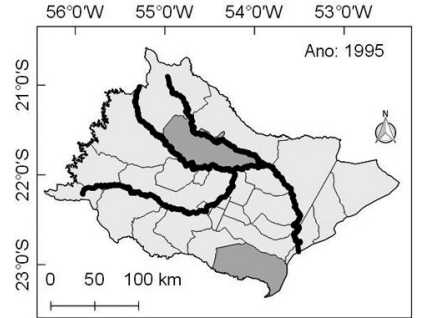

SRC: SIRGAS 2000

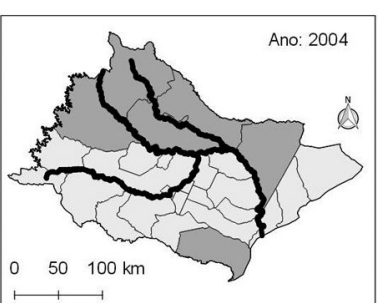

Escala numérica 1:7.770.000

Legenda

Municipios da Bacia do Ivinhema que apresentam cultivo de cana de açúcar

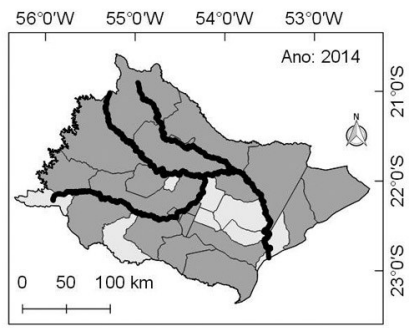

Malha Digital:

IBGE - Instituto Brasileiro de Geografia e Estatistica e ANA - Agência Nacional das Águas

Fonte de dados:

RAIS - Relação Anual de Informações Sociais

Figura 5 - Municípios da UPG Ivinhema que apresentam cultivo de cana de açúcar para os respectivos anos de 1995, 2004 e 2014

Fonte: elaboração própria a partir dos dados de RAIS-CAGED-MTE, disponível em BRASIL (2018).

Ainda na tabela 2 pode-e perceber que o único valor para o qual o Índice de Hoover é menor do que 0,5 , ou seja, próximo de zero, é a criação de bovinos $(0,43)$. $\mathrm{O}$ que indica tal atividade como a mais bem distribuída entre os municípios da UPG Ivinhema. Todavia, mesmo a criação de bovinos, apresentando a melhor distribuição, tal setor possui municípios com um número maior de empregos formais quando comparado aos demais conforme pode-se averiguar pela figura 6 .

Na tabela 3, apresentam-se os municípios em que os valores do coeficiente de especialização foram maiores que 0,5 para algum dos anos de 1995, 2004 eD ou 2014. E, na figura 7, tem-se o percentual de empregos formais em cada um dos setores de criação e cultivo, como também de serviços na agricultura e pecuária. Nesta perspectiva a figura 7 demonstra o percentual de emprego alocado nas atividades de criação, cultivo e serviços, sendo apresentados somente os resultados que são relevantes do ponto de vista do indicador (Tabela 3). 


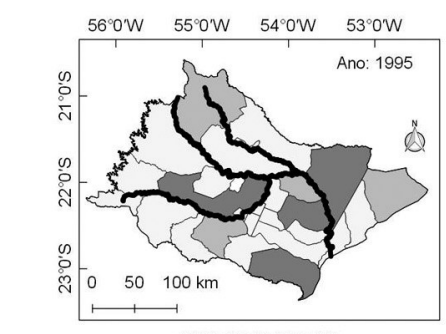

SRC: SIRGAS 2000

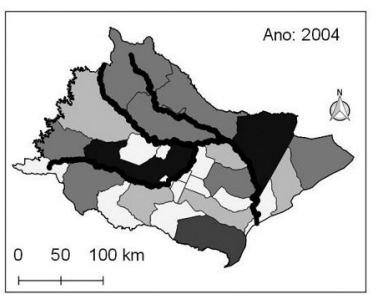

Escala numérica 1:7.770.000

Quantitativo de emprego formal na criação de bovinos:

$10-200 \square 200-400 \square 400-600$ $600-800$ $800-1000$

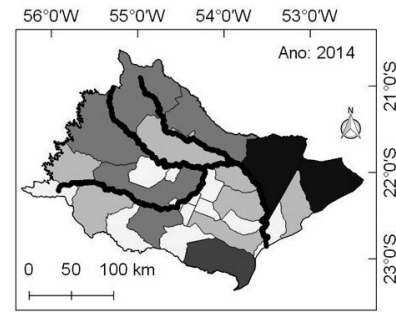

Malha Digital:

IBGE - Instituto Brasileiro de Geografia e

Estatistica e ANA - Agência Nacional das Águas

Fonte de dados:

RAIS - Relação Anual de Informações Sociais

Figura 6 - Quantidade de Emprego Formal na criação de bovinos para a UPG Ivinhema nos anos de 1995, 2004 e 2014

Fonte: elaboração própria a partir dos dados de RAIS-CAGED-MTE, disponível em BRASIL (2018).

Por exemplo, para cada ano (1995, 2004 e 2014) temos 25 municípios, mas em sua maioria com valores do coeficiente inferiores à 0,5 o que informa serem valores próximos de zero, e portanto com uma distribuição do emprego formal entre setores semelhante à da UPG. Assim, optou-se por mostrar somente os resultados em que os municípios que apresentam diferenciação da estrutura produtiva em relação à região da bacia hidrográfica, ou seja, superiores à 0,5 para qualquer dos anos de 1995, 2004 e 2014. É importante destacar que a distinção entre cultivo de cereais para grãos e cultivo de soja utilizado neste trabalho, toma por base a Classificação Nacional de Atividade Econômica - CNAE D95 do IBGE.

Tabela 3 - Municípios da UPG Ivinhema que apresentam Coeficiente de Especialização para a Bacia do Ivinhema com magnitude maior ou igual à 0,5 para qualquer dos anos de 1995, 2004 ou 2014

\begin{tabular}{lccc}
\hline Município & $\mathbf{1 9 9 5}$ & $\mathbf{2 0 0 4}$ & $\mathbf{2 0 1 4}$ \\
\hline Douradina & 0,6 & 0,5 & 0,5 \\
\hline Fátima do Sul & 0,4 & 0,6 & 0,4 \\
\hline Laguna Carapã & 0,2 & 0,5 & 0,6 \\
\hline Novo Horizonte do Sul & 0,4 & 0,5 & 0,6 \\
\hline Vicentina & 0,4 & 0,3 & 0,6 \\
\hline
\end{tabular}

Fonte: elaboração própria a partir dos dados de RAIS-CAGED-MTE, disponível em BRASIL (2018). 

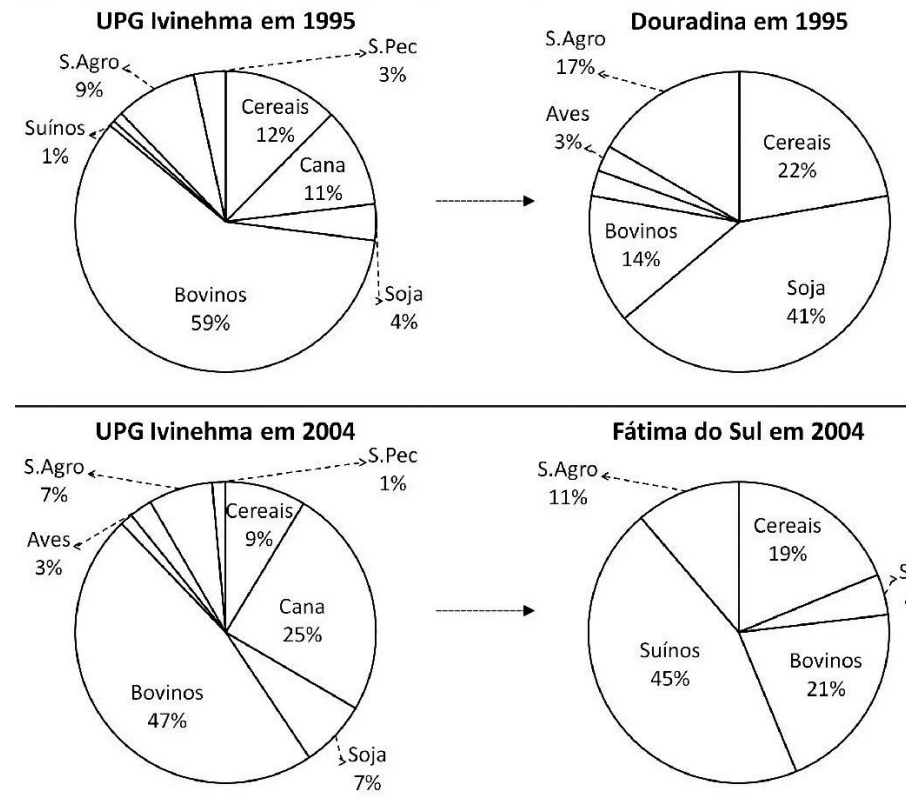

Fátima do Sul em 2004

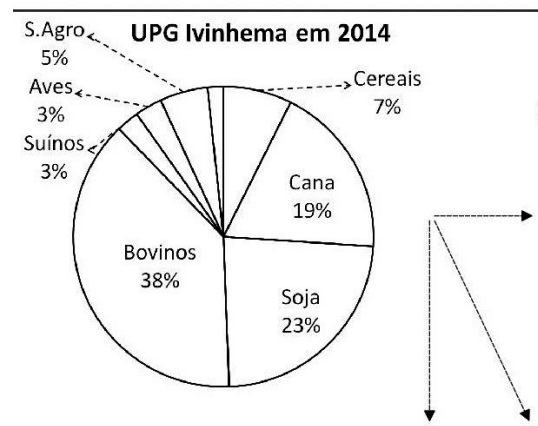

Aves $<_{<}$Laguna Carapã em 2014

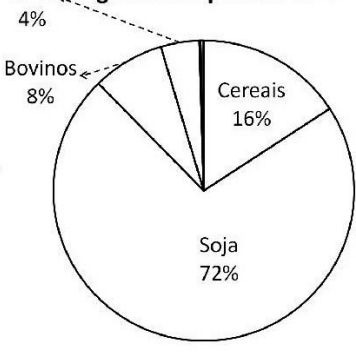

Novo Horizonte do Sul em

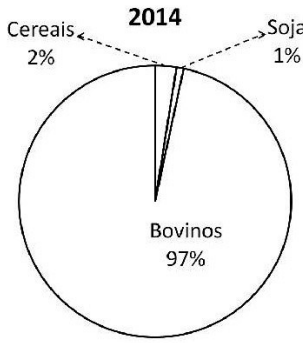

S.Agro $\_$Vicentina em 2014,, Cereais

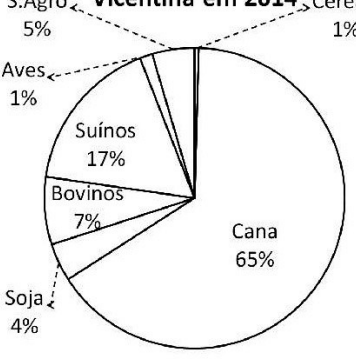

Figura 7 - Participação percentual de emprego formal nas atividades agropecuárias

Fonte: elaborado pelos autores a partir dos dados de RAIS-CAGED-MTE, disponível em BRASIL (2018). 
Por meio da tabela 2 e figura 7 pode-se auferir que o emprego formal na UPG Ivinhema estava concentrada de forma majoritária na criação de bovinos em 1995, enquanto que em Douradina tal percentual repousava sobre o cultivo de soja. Neste caso, Douradina apresentava especialização em soja em relação à UPG Ivinhema. Já em 2004, na UPG Ivinhema, tem-se um pequeno recuo percentual na participação da criação de bovino em favor da expansão do cultivo de cana de açúcar, ao passo que em Fátima do Sul o emprego formal está, em sua maior parte, na criação, em primeiro lugar, de suínos e, em segundo lugar de bovinos.

Neste contexto pode-se afirmar que a estrutura fundiária ainda herdada da colonização oficial, permanece como rugosidade e disponibiliza o trabalho familiar, em áreas que predominam entre 10 e 100 hectares, utilizadas nos sistemas de criação de aves em integração com a agroindústria.

Em 2014, enquanto a UPG Ivinhema apresenta altos percentuais de emprego formal para a criação de bovino e cultivos de soja e cana de açúcar, tem-se Laguna Carapã com alto percentual de emprego formal para o cultivo de soja, e Vicentina para cana de açúcar. Ao passo que a criação de bovinos ocupa majoritariamente o emprego formal em Novo Horizonte do Sul.

Com relação ao coeficiente de reestruturação, seus valores podem ser conferidos na tabela 4, na qual consta somente os municípios que apresentaram valores do coeficiente superiores à 0,5 para o período compreendido entre 1995 a 2014.

\section{Tabela 4 - Municípios da UPG Ivinhema que apresentam Coeficiente de Reestruturação maior que 0,5 para o período entre 1995-2014}

\begin{tabular}{cc}
\hline Município & $\mathbf{1 9 9 5 - 2 0 1 4}$ \\
\hline Caarapó & 0,7 \\
\hline Laguna Carapã & 0,7 \\
\hline Maracaju & 0,6 \\
\hline Vicentina & 0,8 \\
\hline
\end{tabular}

Fonte: elaboração própria a partir dos dados de RAISCAGED-MTE, disponível em BRASIL (2018).

Por meio da figura 8 pode-se auferir que os municípios nos quais ocorreu reestruturação produtiva, ou seja, houve substituição da criação de bovinos para a disseminação do cultivo de soja (em Laguna Carapã e Maracaju). Como também a supressão da criação de gado bovino para a expansão do cultivo de cana de açúcar em Caarapó e Vicentina. O arrendamento para a cana foi opção em relação ao custo para reforma das pastagens, bem como o preço da soja no mercado internacional tornou-se atrativo em comparação com o custo da arroba, abatida nos frigoríficos internacionalizados que passaram a subordinar o pecuarista em função da concentração do setor.

Os dados revelam, portanto, uma macroestratégia de ação do mercado global e dos atores de produção regionais para com a UPG Ivinhema. As atividades vinculadas à criação de bovinos, que possuem um aspecto mais descentralizador perante os dados, foram e estão sendo, em boa parte, substituídas pelas atividades de cultivo de grãos (como se vê nos municípios de Laguna Caarapã e Maracajú) e, que, por sua vez, agregam valor direto ao próprio setor da pecuária, com a possibilidade de maior produção de ração animal. Ou seja, a atividade de produção de grãos, em especial da soja, "turbina" o mercado pecuário regional, agregando capital. 

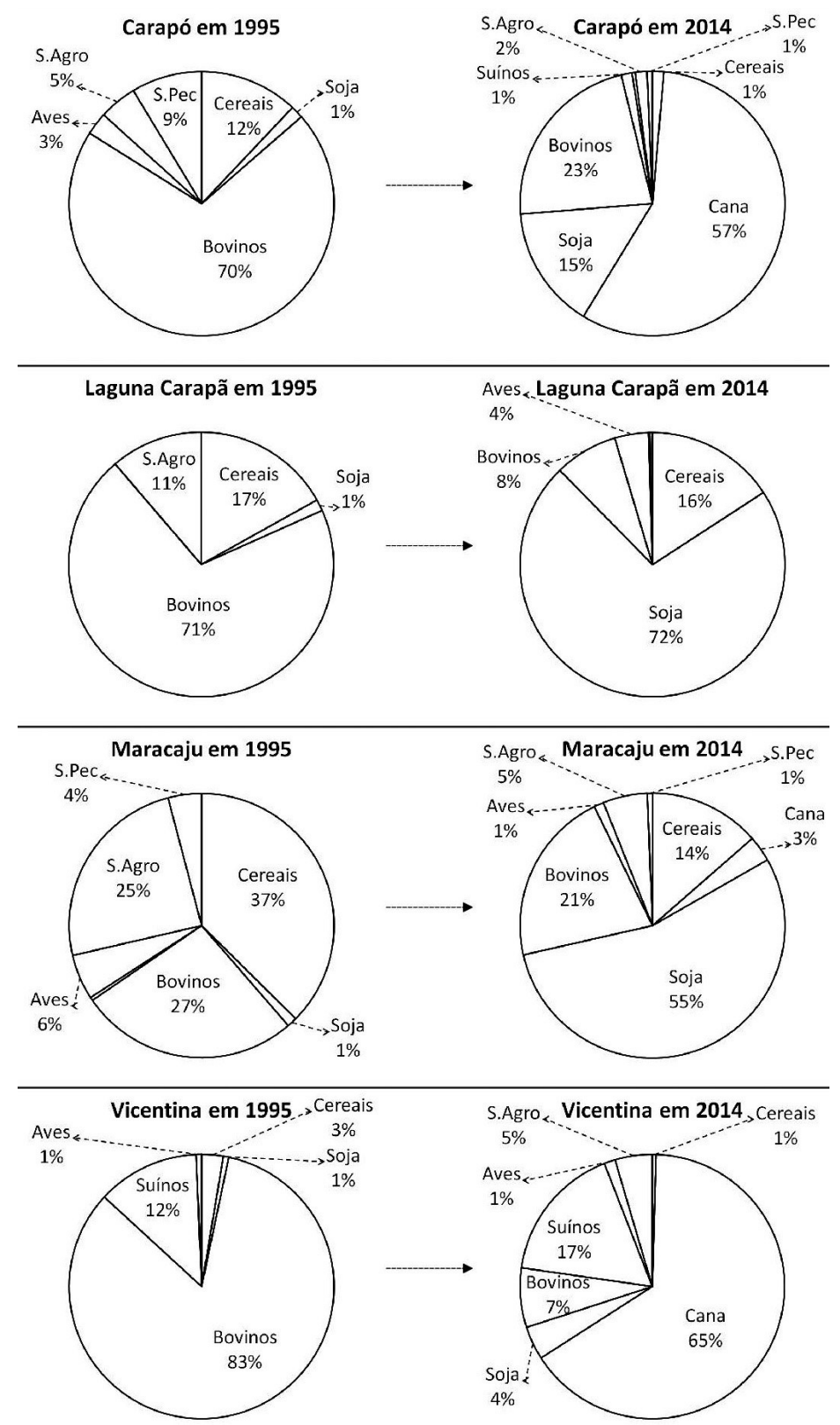

Figura 8 - Emprego Formal para municípios selecionados da UPG Ivinhema nos ano de 1995 e 2014

Onde "S.Pec" corresponde à Serviços para Pecuária e "S.Agro" à Serviços para Agricultura. Fonte: elaboração própria a partir dos dados de RAIS-CAGED-MTE, disponível em BRASIL (2018). 
No mais, parte da produção de grãos, exportada para o mercado externo também impulsiona o setor bovino de vários países, que compram o grão e o farelo de soja para fabricação de ração. O que se percebe é que mesmo a modificação da produção do principal produto em alguns municípios da UPG Ivinhema, no período de 1995-2014, não significa, necessariamente, mudança do padrão de produção, que continua a ser o tripé "grãos $\mathrm{x}$ insumos agrícolas (ração animal) x setor pecuário". 0 que existe, de fato, é uma agregação de capital regional para um macromercado que valoriza o tripé de produção "grãos $\mathrm{x}$ insumos agrícolas (ração animal) $\mathrm{x}$ setor pecuário". Não significa, portanto, que o setor pecuário está "definhando", pelo contrário.

Com relação à produção de cana-de-açúcar, a expansão vertiginosa das áreas de cana-de-açúcar, na UPG Ivinhema, se constitui como um nicho de produção de natureza fortemente nacional (do Brasil). O Brasil, como uma das poucas nações que produzem historicamente etanol como combustível, tem, na produção deste álcool, uma forte fonte de ganho de capital no setor primário. O que chama a atenção, para com a produção de cana-de-açúcar, é a migração de sua produção de áreas que possuem solos menos férteis, para áreas que possuem solos mais férteis, o que é facilmente verificável na figura 5. Esta expansão das áreas dos canaviais, das áreas de Latossolos Vermelho-Amarelos, para as áreas de Latossolos Roxos, se dá por causa da forte oportunidade de ganho de lucros por parte do proprietário rural, para com a produção de cana-de-açúcar e de diversos donos de usinas de cana, que compram a produção regional de cana. A hipótese de produção de cana-de-açúcar, como uma alternativa para áreas de solos mais pobres, é substituída, portanto, como uma alternativa de ganho rápido de capital, não importando a configuração física do território. Este processo de expansão dos canaviais ocorre, também, em outras UPGs do Estado do Mato Grosso do Sul, tal como na vizinha UPG Amambai.

\section{CONSIDERAÇÕES FINAIS}

A macroestratégia de produção da UPG Ivinhema possui uma natureza fortemente agressiva, onde se consolida a permanência da grande propriedade rural e, consequentemente, da centralização fundiária. Este modo de produção contrasta com as estratégias de produção provenientes da denominada "agricultura familiar", que preza pelo majoritário cultivo de produtos que possuam um alcance de venda regional mas que possam ser produzidos pela pequena propriedade, tal qual a produção de vários tipos de legumes, cereais, verduras e frutas (hortifruticultura). Convém lembrar que boa parte dos produtos alimentícios que são consumidos, no atacado e no varejo, é proveniente da produção das pequenas propriedades. Assim sendo, é inegável que existe um esquema de produção voltado ao setor "alimentício direto" (de produtos elaborados diretamente para a mesa do consumidor) e outro esquema de produção vinculado ao macromercado, de forte apelo ao agregamento de capital (esquema soja-ração-carne).

Convém ressaltar que este macromercado, que regulamenta e impulsiona a produção macroterritorial da UPG Ivinhema, possui direta e umbilical participação para com as políticas territoriais do Estado do Mato Grosso do Sul, sejam com as políticas hídricas, com a criação dos Comitês de Bacias Hidrográficas e com o desenvolvimento do Plano Estadual de Recursos Hídricos (PERH-MS, 2010), seja com o desenvolvimento de documentos tais como o Zoneamento Ecológico-Econômico do Estado do Mato Grosso do Sul (2006). A criação do Comitê de Bacia Hidrográfica do Ivinhema, terceiro comitê de bacia em vigência no Estado do Mato Grosso do Sul 


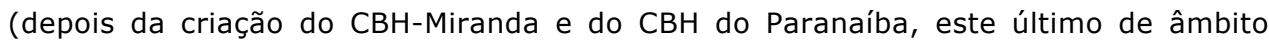
nacional), é uma evidência clara do poder de ação do macromercado e dos atores de produção deste mercado global na UPG Ivinhema. No comitê de bacias hidrográficas, inserida em uma esfera de ação, em princípio, legalmente "descentralizada", segundo os moldes da Lei 9433/1997 e da Lei Estadual 2406/2002, o setor agroindustrial planeja ações no âmbito da cobrança hídrica, vista por este setor como um dos mais estratégicos pontos de discussão, além do forte debate sobre a utilização de maiores montantes hídricos para o crescimento das atividades do agribusiness, este, por sua vez, na discussão dos procedimentos de outorga de recursos hídricos, que já é um tema de direta responsabilidade do Conselho de Recursos Hídricos do Estado, mas cuja "arena de debates" existe no seio do Comitê de Bacias Hidrográficas.

Nesta esfera, onde Estado e Macromercado tecem um jogo de produção na ordem de milhões, bilhões de dólares, envolvendo diretamente o PIB do Brasil, existem também setores, grupos especiais, que também se encontram inseridos nas transformações espaciais recentes da UPG Ivinhema, tal qual: 1) as já citadas propriedades que trabalham com a denominada "agricultura familiar"; 2) de diversos grupos indígenas que vivem na área da UPG Ivinhema, que manifestam a sua existência como atores regionais, clamando pela aquisição de terras (que denominam o seu tekohá) e pelo respeito de suas tradições e cultura (que, muitas vezes, apresentam significados muito distantes dos valores propagados pelo macromercado); 3 ) dos assentamentos e acampamentos rurais na área de estudo, que possuem estreita ligação com os dois primeiros grupos e, juntamente com os dois grupos citados, configuram um grupo de atores territoriais que se manifestam como um polo de discussão e de resistência, perante um mecanismo de produção que não admite outra forma de ordenamento territorial que não seja através da busca pela mais-valia, mas que possui a capacidade camaleônica de incorporar e se adaptar a novas situações e incorporação de novos grupos que possam atrapalhar planos e metas de produção.

Por último, mas não menos importante, convém destacar que inserida nesta esfera de disputa do modo de produção agrícola, que perspassa para a esfera agrária e social, há a questão ambiental, onde as áreas conservadas e preservadas da UPG Ivinhema se encontram em cada vez mais elevada "tensão ambiental". Estas áreas, que já são limitadas territorialmente, encontram-se cada vez mais visadas, sendo classificadas como recursos territoriais ou mesmo de "benfeitorias", termos técnicos e mercadológicos que enfatizam conceitos marxistas da relação Sociedade versus Natureza, como o de Natureza Externa de Smith (1984). Nestas áreas raras e visadas, são identificados enclaves de Mata Atlântica, Cerrado, matas ciliares e áreas úmidas.

\section{REFERÊNCIAS}

BRASIL. MINISTÉRIO do Trabalho e Emprego - MTE. Relação Anual de Informações Sociais ação Anual de Informações Sociais - RAIS. Brasília: disponível em <http://www.mte.gov.br/rais/default.asp>. Acessado em dez. 2018.

BRASIL. LEI 9433/97 - Política Nacional de Recursos Hídricos. http:// www.ana.gov.br/Institucional/Legislacao/leis/lei9433.pdf - Acesso em 06 dez. 2016.

FRATA, Angela Maria; FARIA, Alcides Bartolomeu de. A expansão da cana-de-açúcar e o recorte em bacias hidrográficas: o etanol na sub-bacia do rio Ivinhema. In: CONGRESSO DA SOCIEDADE BRASILEIRA DE ECONOMIA E SOCIOLOGIA RURAL, 48, 2010, Campo Grande. Anais... . Campo Grande: Sober, 2010. p. 1 - 21. Disponível em: <http://www.sober.org.br/palestra/15/500.pdf>. Acesso em: 04 set. 2016. 
HOFFMANN, Rodolfo. Estatística parar Economistas. 4. ed. São Paulo: Pioneira Thomson Learning, 2006. 432 p.

LIMA, Ana Carolina da Cruz; SIMÕES, Rodrigo Ferreira. Centralidade e emprego na região Nordeste do Brasil no período 1995/2007. Nova Econ., [s.l.], v. 20, n. 1, p.3983, abr. 2010. FapUNIFESP (SciELO). http://dx.doi.org/10.1590/s010363512010000100002.

MALHA municipal digital do Brasil de 2010. Rio de Janeiro: IBGE, [2016]. Disponível em: <ftp://geoftp.ibge.gov.br/malhas_digitais/> . Acesso em: Dez. 2018.

MATO GROSSO DO SUL. Lei Estadual 2406/2002, Política Estadual de Recursos Hídricos <http://www.imasul.ms.gov.br/wp-content/uploads/sites/74/2015/11/LEIN\%C2\%BA-2406-2002.pdf> - Acesso em 06 dez. 2016.

MELO, Luzia Maria Cavalcante de; SIMÕES, Rodrigo Ferreira. Crescimento Industrial no Nordeste: Novo Dinamismo, Velho Padrão. RDE: Revista de Desenvolvimento Econômico, Salvador, v. 11, n. 20, p.56-66, jul. 2009. Disponível em: <http:// www.revistas.unifacs.br/index.php/rde/article/view/1061/839>. Acesso em: 12 nov. 2016.

MONASTERIO, Leonardo. Indicadores de Análise Regional e Espacial. In: CRUZ, Bruno de Oliveira et al (Org.). Economia Regional e Urbana: Teorias e métodos com ênfase no Brasil. Brasília: Ipea, 2011. Cap. 10. p. 315-332. Disponível em: <http:// repositorio.ipea.gov.br/bitstream/11058/3008/1/Livro_Economia regional e urbana_teorias e métodos com ênfase no Brasil.pdf>. Acesso em: 31 out. 2016.

MOREIRA, Ruy. Sociedade e Espaço Geográfico no Brasil. São Paulo: Editora Contexto, 2015. 159 p.

OLIVEIRA, Henrique de; URCHEI, Mário Artemio; FIETZ, Carlos Ricardo. Aspectos Físicos e Econômicos da Bacia Hidrográfica do Rio Ivinhema. Dourados: Embrapa Agropecuária Oeste, 2000. Disponível em: <http://ainfo.cnptia.embrapa.br/digital/ bitstream/item/65676/1/DOC25-00-ivi.pdf>. Acesso em: 04 set. 2016.

PLANO ESTADUAL DE RECURSOS HÍDRICOS DO MATO GROSSO DO SUL. Campo Grande : Editora UEMS, Governo do Estado do Mato Grosso do Sul, 2010. 194 p.

SMITH, N. Uneven development: capital, nature and the production of space. Oxford: Blackwell, 1984. 198 p.

ZONEAMENTO ECOLÓGICO-ECONÔMICO DO ESTADO DO MATO GROSSO DO SUL. Campo Grande: Mato Grosso do Sul, vol. 1, 2, 3, 2006.

Recebido em novembro de 2018

Aceito em dezembro de 2018 